\title{
Erratum to: Entertainment Computing - ICEC 2009
}

\author{
Stéphane Natkin and Jérôme Dupire \\ Conservatoire National des Arts et Métiers, CEDRIC, 292, rue St. Martin, \\ 75141 Paris Cedex 03, France \\ \{stephane.natkin, jerome.dupire\}@cnam.fr
}

\section{Erratum to: \\ S. Natkin and J. Dupire (Eds.) \\ Entertainment Computing - ICEC 2009 DOI: $10.1007 / 978-3-642-04052-8$}

The book was inadvertently published with an incorrect name of the copyright holder. The name of the copyright holder for this book is: (c) IFIP International Federation for Information Processing. The book has been updated with the changes.

The updated original online version for this book can be found at DOI: $10.1007 / 978-3-642-04052-8$ 